\title{
REMOÇÃO DO CORANTE VERDE MALAQUITA USANDO COLUNA DE ADSORÇÃO
}

\author{
C. R. de LACERDA, M. C. e LIMA, P. de C. RESENDE, P. G. M. SOARES e M. S. \\ BATISTA
}

Universidade Federal de São João del Rei, Campus Alto Paraopeba, Departamento de Engenharia Química

E-mail: camilaraqueldelacerda@gmail.com

RESUMO - A remoção de cor dos efluentes líquidos é um dos principais problemas da indústria têxtil devido à coloração intensa em pequenas quantidades de corantes. Tendo em vista esta problemática e considerando que a adsorção é um método eficaz para tratamento de efluentes contendo corantes, o objetivo deste trabalho foi construir uma coluna de adsorção de leito fixo usando carvão ativado como adsorvente para tratamento de água contendo o corante verde malaquita. Construiu-se a curva padrão do corante e realizaram-se os testes de adsorção utilizando-se uma solução aquosa de verde malaquita com concentração de $7,5 \times 10^{-3}$ g.L $\mathrm{L}^{-1} \mathrm{e}$ vazões de alimentação de $113 \mathrm{~mL} \cdot \mathrm{min}^{-1}$ e $213 \mathrm{~mL} \cdot \mathrm{min}^{-1}$. Os testes foram realizados até que não houvesse mais mudança visual de cor da solução e dos valores de absorbância. As curvas de ruptura mostraram que para a maior vazão o ponto de ruptura é alcançado mais rapidamente (160 min) do que para a menor vazão $(925 \mathrm{~min})$. Calcularam-se também as eficiências de utilização do leito para cada vazão e foi observado que a menor vazão apresenta maior eficiência para remoção do corante $(52,3 \%)$, fato que foi atribuído ao maior tempo de contato do corante com o adsorvente.

\section{INTRODUÇÃO}

Nos efluentes da indústria têxtil, a maior parte da carga orgânica dos corantes é representada por agentes engomantes (amido), sendo facilmente degradada pelos processos biológicos tradicionais. No entanto, a cor, originada por uma grande variedade de corantes reativos, tipo azo com elevado potencial carcinogênico e mutagênico, mostra-se bastante resistente a este tipo de procedimento (Braga et. al., 2002). Estima-se que de 1 a $15 \%$ dos corantes utilizados são perdidos durante o processo de tingimento e liberados no efluente, causando poluição das águas, interferindo na solubilidade de gases nos corpos receptores, reduzindo a capacidade de regeneração dos corpos hídricos e alterando os processos de fotossíntese (Vasques, 2008; Guarantini e Zanoni, 2000).

Os corantes normalmente são recalcitrantes ou apresentam uma cinética de degradação muito lenta para processos biológicos convencionais, resultando em efluentes finais com coloração ainda muito intensa (Kunz et al., 2002). Dentre os vários métodos químicos e físicos existentes, o processo de adsorção é uma técnica efetiva que tem sido empregada com sucesso na remoção de cor das águas contaminadas (Elmoubarki et al., 2015). Muitos adsorventes vêm sendo testados para reduzir as concentrações dos corantes das soluções aquosas e o carvão ativado é considerado um adsorvente bastante efetivo, que possui alta 
capacidade de adsorção, baixa reatividade térmica, resistência a grandes variações de pH no meio e capacidade de regeneração (Elmoubarki et al., 2015; Netpradit et al., 2003).

O corante verde malaquita possui alta solubilidade em água e apresenta colorações diferentes de acordo com o pH, sendo amarelo em $\mathrm{pH}$ abaixo de 2, verde em $\mathrm{pH} 2$, verde azulado em pH 11 e incolor em pH 14 (Peruzzo, 2003). Sua molécula é catiônica e pertence à família dos trifenilmetanos, com três anéis benzênicos, e sua fórmula química é representada por $\mathrm{C}_{23} \mathrm{H}_{25} \mathrm{~N}_{2}$. A absorção máxima de radiação eletromagnética ocorre em $617 \mathrm{~nm}$ e o corante apresenta uma banda de absorção na região vermelha do espectro eletromagnético (Patres, 2005).

A FDA (Food and Drug Administration) verificou que o verde malaquita deixa resíduos na carne de animais como o bagre, truta, tilápia, basa, salmão e camarão, proibindo assim seu uso. Este corante, ao ser absorvido pelo organismo, é metabolizado na forma de carbinol que, entrando na célula, é novamente metabolizado e transformado em leucomalaquita, a qual permanece no organismo por longos períodos e produz efeitos tóxicos no ser humano, como o câncer no fígado (FDA, 2016).

Tendo em vista a necessidade de remoção do corante verde malaquita de água residuais, o objetivo deste trabalho foi construir uma coluna de adsorção de leito fixo, utilizando carvão ativado como adsorvente, para remoção deste corante.

\section{METODOLOGIA}

\subsection{Determinação da Concentração de Verde Malaquita}

Construiu-se a curva padrão do corante, com concentração máxima de 0,020 g.L $\mathrm{L}^{-1}$.

Os valores das absorbâncias foram medidos em $617 \mathrm{~nm}$, no espectrofotômetro UV (Micronal modelo AJX-1600), pois nesse comprimento de onda o corante verde malaquita apresenta máxima absortividade.

\subsection{Montagem da Coluna de Adsorção}

A coluna de adsorção foi construída com $600 \mathrm{~mm}$ de altura, $5 \mathrm{~mm}$ de diâmetro interno, $130 \mathrm{~mm}$ de esferas de vidro na parte inferior, $130 \mathrm{~mm}$ de esferas de vidro na parte superior, $20 \mathrm{~mm}$ de lã de vidro antes e após o carvão ativado e $300 \mathrm{~mm}$ de carvão ativado (7,36 g), seguindo a ordem mostrada na Figura 1. Os materiais utilizados foram: cilindro de acrílico, tubos PVC, bomba peristáltica, válvula esfera (3/4"), tanques de armazenamento de $12 \mathrm{~L}$ e mangueira (3/4"). 
Figura 1 - Desenho da coluna com as respectivas dimensões em $\mathrm{mm}$.

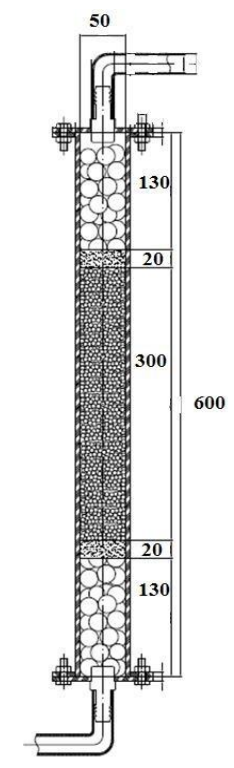

\subsection{Testes de Adsorção}

Preparou-se uma solução aquosa com concentração $7,5 \mathrm{mg} . \mathrm{L}^{-1}$ de verde malaquita, a qual foi utilizada como modelo para tratamento. Duas diferentes vazões foram testadas, sendo elas $113 \mathrm{~mL} \cdot \mathrm{min}^{-1}$ e $213 \mathrm{~mL} \cdot \mathrm{min}^{-1}$. Coletaram-se amostras da solução final, em intervalos de 10 min, e mediram-se as absorbâncias no espectrofotômetro. Os testes foram realizados até que não se observasse mais mudança de coloração tanto visual quanto pela medida de absorbância no espectrofotômetro. Com os dados coletados e calculados foram feitas as curvas de ruptura para as vazões de $113 \mathrm{~mL} \cdot \mathrm{min}^{-1}$ e $213 \mathrm{~mL} \cdot \mathrm{min}^{-1}$. Calcularam-se as eficiências

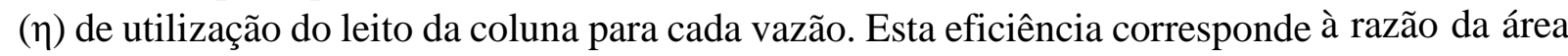
acima da curva de ruptura, depois do tempo de ruptura até a exaustão $\left(\mathrm{A}_{2}\right)$, pela área total acima da curva de ruptura $\left(\mathrm{A}_{1}+\mathrm{A}_{2}+\mathrm{A}_{3}\right)$, conforme Equação 1 (Roteiro: EQ-801- Laboratório de Engenharia Química III, UNICAMP).

$$
\mathrm{\eta}=\frac{A_{2}}{A_{1}+A_{2}+A_{3}}
$$

Calculou-se também a capacidade de adsorção do leito (q), para cada vazão, a partir da curva de ruptura, considerando a saturação do leito, um balanço de massa e monitorando a concentração de saída em função do tempo, Equação 2, em que $\mathrm{C}_{0}$ é a concentração de alimentação, $Q$ é a vazão de operação, $m_{s}$ é a massa de adsorvente e $t_{\text {sat }}$ é o tempo de ruptura (Barbosa et al., 2014).

$$
q=\frac{C_{0} \cdot Q \cdot t_{s a t}}{1000 m_{s}}
$$




\section{RESULTADOS E DISCUSSÃO}

Na Figura 2 se apresenta a curva padrão do verde malaquita, na faixa de $0-0,020$ g.L - $^{-1}$. Note que os resultados mostraram uma relação linear entre a absorbância e a concentração de verde malaquita, com coeficiente de correlação 0,9981 .

Figura 2 - Curva padrão experimental do verde malaquita.

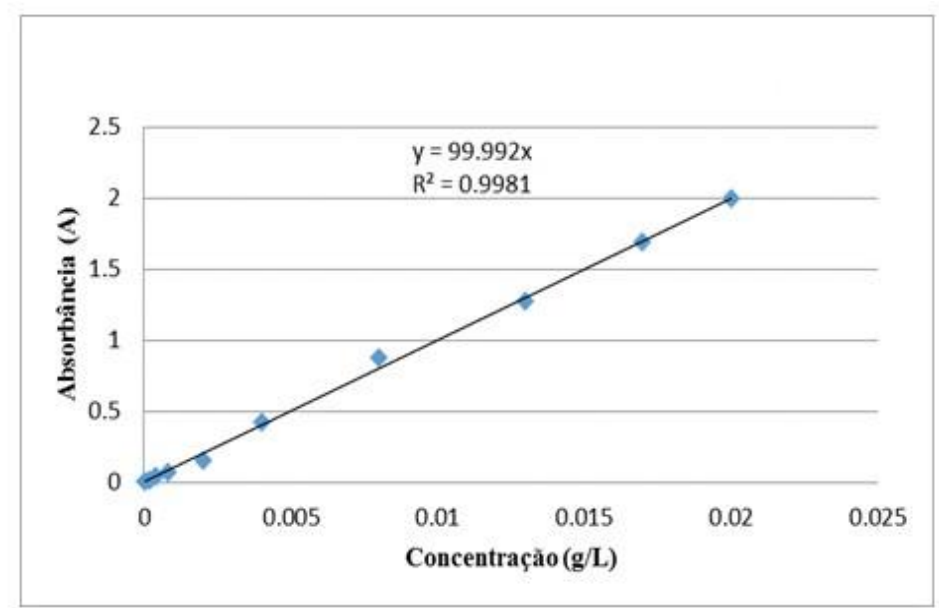

Um dos fatores mais importantes no projeto de uma coluna de adsorção de leito fixo é predizer quando a coluna alcançará o ponto de saturação. Nesse sentido, pode-se descobrir o tempo de trabalho da coluna a partir da análise da curva de ruptura. $\mathrm{O}$ tempo de trabalho da coluna corresponde ao tempo em que a coluna atinge o ponto de ruptura ou ponto de quebra ("Breakpoint"). A curva usualmente tem forma de S, mas em determinados casos, ela pode se apresentar diferente, como plana ou em degrau. A forma da curva pode variar dependendo da taxa de remoção, da velocidade do fluido, da concentração inicial de corante, do comprimento e do diâmetro da coluna (Peruzzo, 2003).

A Figura 3 apresenta a curva de saturação da coluna de adsorção em função do tempo, para a vazão de $113 \mathrm{~mL} \cdot \mathrm{min}^{-1}$. Como se pode observar, o tempo de trabalho da coluna de leito fixo, para a vazão de $113 \mathrm{~mL} \cdot \mathrm{min}^{-1}$, é de 925 minutos, quando $C / \mathrm{C}_{0}=0,0534$, ou seja, até atingir esse ponto de ruptura a coluna opera com níveis determinados e permitidos de concentração estabelecidos pela Resolução 357/05 do CONAMA. Tal Resolução diz que corantes provenientes de fontes antrópicas devem ser virtualmente ausentes e que a cor verdadeira deve possuir o nível de cor natural do corpo de água (Brasil. Conselho Nacional do Meio Ambiente - CONAMA).

A Figura 4 apresenta a curva de saturação da coluna de adsorção em função do tempo para a vazão de 213 mL.min ${ }^{-1}$. Note que o tempo de uso da coluna é de 160 minutos, quando $\mathrm{C} / \mathrm{C}_{0}=0,055$. Como foi dito anteriormente, a coluna apenas opera de maneira eficaz até atingir este ponto. 
Figura 3 - Curva de ruptura para a vazão de $113 \mathrm{~mL} \cdot \mathrm{min}^{-1}$.

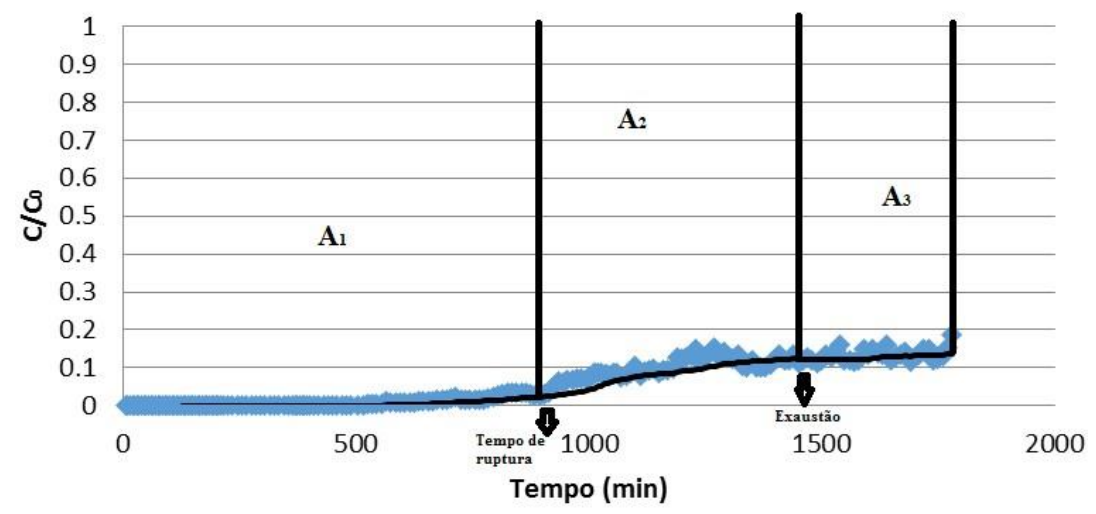

Figura 4 - Curva de Ruptura para a vazão $213 \mathrm{~mL} \cdot \mathrm{min}^{-1}$.

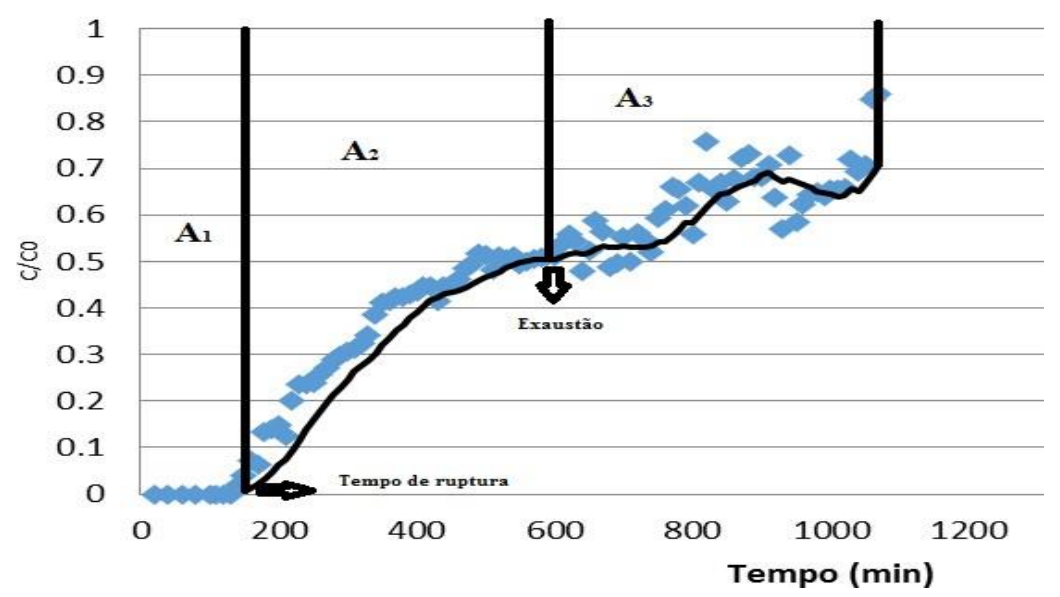

Comparando os resultados das Figuras 3 e 4 observa-se que o ponto de ruptura para a curva referente à vazão de $213 \mathrm{~mL} \cdot \mathrm{min}^{-1}$ é alcançado em um tempo muito menor que para a vazão de $113 \mathrm{~mL} \cdot \mathrm{min}^{-1}$.

Observando os perfis das curvas nas Figuras 3 e 4 pode-se traçar uma previsão para as curvas até a saturação e calcular as eficiências de remoção de verde malaquita. Para a vazão de $113 \mathrm{~mL} \cdot \mathrm{min}^{-1}$ a eficiência foi de $52,3 \%$ e para a vazão de $213 \mathrm{~mL} \cdot \mathrm{min}^{-1}$ foi de $28,8 \%$. Pode-se observar que a coluna de leito fixo que operou com a menor vazão e foi mais eficaz, provavelmente deve-se ao fato de o verde malaquita apresentar maior tempo de contato com o leito, e assim o maior tempo de contato favoreceu a adsorção do corante na superfície do carvão ativado.

Outro parâmetro que foi calculado para cada vazão foi a capacidade de adsorção da coluna, utilizando a Equação 2. Para a menor vazão, obteve-se uma capacidade de adsorção de 0,107 mg de corante. $\mathrm{g}^{-1}$ de adsorvente e para a maior vazão o valor obtido foi de $0,035 \mathrm{mg}$ de corante. $\mathrm{g}^{-1}$ de adsorvente. Nota-se que o aumento da vazão diminui a capacidade de adsorção da coluna, pois ocorre uma redução do tempo de residência para que a adsorção ocorra, e por isto a capacidade da coluna reduz.

\section{CONCLUSÃO}

De acordo com os resultados obtidos pode-se notar a importância de se avaliar o tempo de trabalho da coluna de adsorção para remover o verde malaquita de forma eficiente. Quando ocorre a saturação, a coluna perde a eficiência e a coloração do corante no efluente 


\section{Congresso Brasileiro de Engenharia Química \\ em Iniciação Científica \\ UFSCar - São Carlos - SP \\ 16 a 19 de Julho de 2017}

aumenta. Para as vazões de $113 \mathrm{~mL} \cdot \mathrm{min}^{-1}$ e $213 \mathrm{~mL} \cdot \mathrm{min}^{-1}$ a eficiência foi de 52,3\% e 28,8\% e a capacidade de adsorção foi $0,107 \mathrm{mg}$ de corante. $\mathrm{g}^{-1}$ de adsorvente e $0,035 \mathrm{mg}$ de corante. $\mathrm{g}^{-1}$ de adsorvente, respectivamente. Pode-se observar que a coluna de leito fixo que operou com a menor vazão apresentou maior eficiência para remover o verde malaquita e também maior capacidade de adsorção, visto que o tempo de contato entre o corante e o carvão ativado foi maior.

\section{REFERÊNCIAS}

BARBOSA, J. G.; FIGUEREDO, C. H. J.; PEREIRA, A. K. A.; NETO, J. R. B.; OSTROSKI, I. C. Adsorção do íon cádmio em colunas de leito fixo utilizando o carvão de osso. X Encontro Brasileiro sobre Adsorção. Guarujá, 2014.

BRAGA, B.; HESPANHOL, I.; CONEJO, J. G. L.; BARROS, M. T. L.; SPENCER, M.; PORTO, M.; NUCCI, N.; JULIANO, N.; EIGER, S. Introdução à Engenharia Ambiental. São Paulo: Prentice Hall, 2002.

BRASIL. CONSELHO NACIONAL DO MEIO AMBIENTE - CONAMA. Resolução nº 357, de 17 de março de 2005. Publicação DOU nº 53, de 18/03/2005, p. 58-63.

ELMOUBARKI, R.; MAHJOUBI, F.Z.; TOUNSADI, H.; MOUSTADRAF, J.; ABDENNOURIA, M.; ZOUHRI, A.; EL ALBANI, A.; BARKA, N. Adsorption of textile dyes on raw and decanted Moroccan clays: Kinetics, equilibrium and thermodynamics. Water Resources and Industry. v. 9, p. 16-29, 2015.

FDA - Food and Drug Administration. Import Alert 16-13-2016. http://www.accessdata.fda.gov/cms_ia/importalert_33.html. Acessado em março de 2017.

GUARANTINI, C. C. I.; ZANONI, M. V. B. Corantes Têxteis. Química Nova. v. 23, n. 1, p. 71-78, 2000.

KUNZ, A.; ZAMORA, P. P.; MORAES, S. G.; DURÁN, N. Novas Tendências no Tratamento de Efluentes Têxteis. Química Nova. v. 25, n. 1, p. 78-82, 2002.

NETPRADIT, S.; THIRAVETYAN, P.; TOWPRAYOON, S. Application of waste metal hydroxide sludge for adsorption of azo reactive dyes. Water Research. v. 37, p. 763$772,2003$.

PATRES, R. A. Verde malaquita como fotossensibilizador em terapia fotodinâmica: Ação bactericida sobre Actinobacillus actinomycetemcomitans - um estudo in - vitro. Dissertação de mestrado. Universidade de São Paulo, São Paulo, 2005.

PERUZZO, L. C. Influência de agentes auxiliares na adsorção de corantes de efluentes da indústria têxtil em colunas de leito fixo. Dissertação de mestrado. Universidade Federal de Santa Catarina, Florianópolis, 2003.

Roteiro: EQ-801- Laboratório de Engenharia Química III. Departamento de Processos Químicos. Universidade Estadual de Campinas. Disponível em http://www.feq.unicamp.br/ mak/Roteiros/carvao.htm. Acesso em 21-04-17.

SHAHALAM, A. B.; BIOUSS, A.; AYOUB, G. M.; ACRA, A. Competitive Adsorption Phenomena of Petrochemicals - Benzene, Toluene, and Xylene in Hexane in FixedBeds of Sands. Water, Air, \& Soil Pollution. v. 95, p. 221-235, 1997.

VASQUES, A. R. Caracterização e Aplicação de Adsorvente para Remoção de Corantes de Efluentes Têxteis em Batelada e Colunas de Leito Fixo. Dissertação de mestrado em Engenharia Química. Universidade Federal de Santa Catarina, Florianópolis, 2008. 